\title{
An hereditary motor neurone disease with progressive denervation of muscle in the mouse: the mutant 'wobbler'
}

\author{
L. W. DUCHEN AND SABINA J. STRICH (With an Appendix by D. S. FALCONER) \\ From the Department of Neuropathology, Institute of Psychiatry, \\ The Maudsley Hospital, London S.E.5, and the Institute of Animal Genetics, Edinburgh
}

More than one hundred hereditary neurological diseases of mice are now on record (Grüneberg, 1952, 1956; Sidman, Green, and Appel, 1965). For many of these conditions only clinical descriptions and genetic data are available and few pathological investigations have been made. This paper describes the clinical and pathological studies of an hereditary disease in mice in which the primary abnormality appears to be located in the perikaryon of motor neurones. The disease arose as the result of a spontaneous mutation in the C57 BL/Fa strain of mice at the Institute of Animal Genetics, Edinburgh. The mutant, which was named 'wobbler' (Falconer, 1956) is transmitted by an autosomal recessive gene $w r$ (see Appendix). The clinical and pathological characteristics of this mutant were briefly described in a preliminary communication (Duchen, Falconer, and Strich, 1966).

\section{THE CLINICAL SYNDROME}

These observations are based on a study of more than 50 affected animals aged from 19 days to more than one year. Mice which are heterozygous for the gene $w r$ are clinically normal, but about $25 \%$ of their offspring may be expected to be homozygous 'wobblers' (wr/wr). The homozygous mice show no clinical abnormality during the first three weeks after birth, but by the fourth week they are smaller than their littermates and always remain so. They have a high-stepping, slightly unsteady gait and a fine tremor of the head. Over the next few weeks there is progressive unsteadiness associated with a wobbling type of gait with the head and front part of the trunk held lower than normally. Weakness of muscles becomes apparent by the fourth or fifth week and is most obvious in the forelimbs, the grip of the forepaws being particularly affected. From the fourth to about the twelfth week there is progressive weakness and wasting especially of the muscles of the head, neck and forelimbs, while the hindlimbs are less affected. The unsteady wobbling gait becomes more obvious and the mouse becomes unable to extend the forepaws at the wrist, so that it ultimately walks on the dorsum of the paws (Fig. 1). In advanced stages of the disease the mouse has great difficulty in using the forelimbs for climbing (Fig. 2) or walking, and pushes itself along with the hindlimbs which are usually less severely affected. The facial muscles are atrophied, giving the snout a pointed appearance and the ears tend to lie back. As in other neurological diseases in mice, the hindlimbs become flexed and adducted instead of extended when the animal is lifted by the tail.

The course of the disease varies somewhat in different mice. Usually after a period of rapid deterioration up to the third or fourth month of age, the progress of the disease seems to slow down and it may even become 'burnt out'. Some affected mice have lived for more than a year in spite of muscle weakness and wasting. In other cases the disease causes more extensive and severe muscle weakness and is fatal by the third or fourth month. There is no clinical evidence of any abnormality in any of the sensory systems. It has proved impossible to breed from affected males or females.

\section{MATERIAL AND METHODS}

Histological studies were made of 40 clinically affected mice ranging in age from 5 weeks to 13 months. Unaffected littermates, some of which may have been heterozygous for the gene $w r$, and normal mice of other strains were used as controls. In order to determine whether there were histological changes before the onset of clinical abnormalities two entire litters, aged 19 and 22 days respectively, derived from known heterozygous parents, were examined. In each litter one mouse showed histological abnormalities.

The mice were killed with chloroform, the thoracic and abdominal cavities opened and the skin over the skull and 


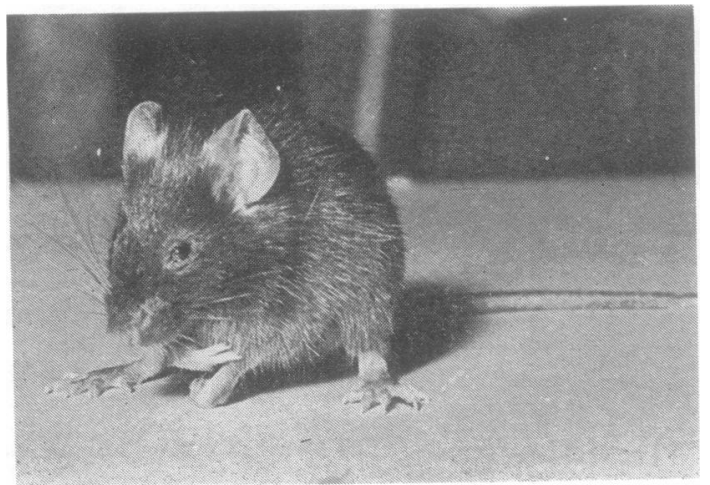

FIG. 1. A 'wobbler' mouse 10 weeks old. Note the abnormal posture. The animal cannot extend the forepaws. The face is thinner than that of a normal mouse.

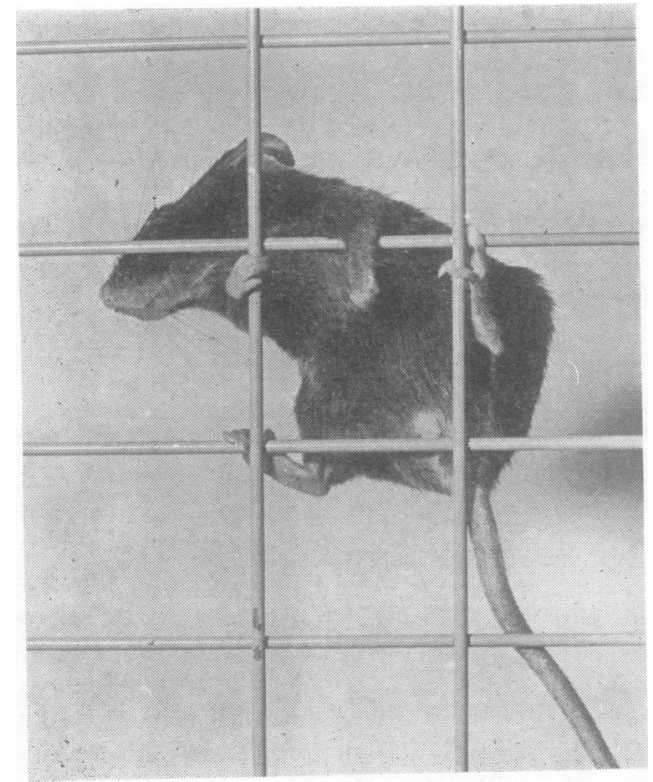

FIG. 2. A 'wobbler' mouse 6 months old climbing on a vertical wire grid. The mouse does not grip with the forepaws but uses the forelimb like a hook. The ears do not stand up because of paralysis of the levator auris longus.

spinal column reflected. The mouse was then immersed in fixative which was either formol-alcohol $(10 \%$ formalin in $60 \%$ alcohol) or formol-calcium (10\% formalin with $1 \%$ calcium acetate). After fixation whole mice were decalcified in formic-citrate solution (65 parts $20 \%$ sodium citrate and 35 parts $90 \%$ formic acid) and blocks of tissue were embedded in paraffin wax or in gelatin for frozen sections. Paraffin sections were made of brain and brain-stem in sagittal or coronal planes and of the trunk and limbs in transverse or longitudinal planes. Much use was made of the 'serial block' method of Beesley and
Daniel (1956) in which consecutive transverse segments of tissue are embedded in one block of wax. With the use of this method the entire brain and spinal cord of several animals of different ages were examined in serial sections. Staining methods used on paraffin sections included haematoxylin and eosin, iron haematoxylin, and van Gieson's mixture; Mallory's phosphotungstic acidhaematoxylin; periodic acid-Schiff; Holzer's method for astrocytes; cresyl violet (Nissl's method) alone or combined with luxol-fast blue (Klüver and Barrera, 1953) to demonstrate myelin; Gallyas's method (1963) for microglia; and Palmgren's (1948) silver method for nerve fibres. Frozen sections of central and peripheral nervous systems were stained for fat with oil-red-O, and nerve fibres were demonstrated in thick $(60 \mu)$ serial sections of whole limbs by Schofield's (1960) method.

\section{HISTOLOGICAL OBSERVATIONS}

The most characteristic abnormality found in all the affected mice was a degeneration of nerve cells of the motor system in the brain-stem and spinal cord, but not in basal ganglia or cerebral cortex. There was progressive denervation of skeletal muscle.

In all animals examined, motor nerve cells in various stages of degeneration were seen side by side with normal-looking cells (Fig. 3). In what appeared to be an early stage, the nerve cell was enlarged, sometimes became rounded, and the Nissl substance of the perikaryon stained poorly (Fig. 4).The nucleus with its prominent nucleolus was central in position as in the normal cell. At a later stage in the degeneration the cell body was filled or partially filled with vacuoles which appeared empty with all the stains used. In some cells the nucleus was eccentric inf position (Fig. 3). In the last stages of degeneration the nerve cells were almost unrecognizable. In these cells the nucleus was surrounded by an ill-defined mass of vacuoles (Fig. 5). No glial or microglial reaction was observed around any of the abnormal cells, nor were glial nodules found in the later stages of the disease. Cells in all stages of degeneration could usually be found in the same animal. Nerve cells showing these changes have never been found in any clinically normal littermates of 'wobbler' mice, nor in mice of any of the other strains which have been studied in this laboratory.

The early changes in skeletal muscle consisted of enlargement of sarcolemmal nuclei and their migration to the centre of the muscle fibre (Fig. 6) Later there was a decrease in the diameter of muscle fibres, first singly, then in groups and eventually involving whole bundles (Fig. 7). This was followed by the appearance of fat between atrophied fibres (Fig. 8).

The pattern of motor innervation of skeletal muscles became abnormal. In the early stages there was sprouting from preterminal axons, and single 
nerve fibres innervated several muscle fibres (Figs. 9 and 10). (In the mouse, as in other mammals, each preterminal nerve fibre normally supplies one muscle fibre.) In later stages there was a marked reduction in the number of motor nerve fibres in the affected muscles. These changes in muscle and nerve fibres are characteristic of progressive motor denervation.

No abnormalities were found in the sensory innervation of structures such as skin, mucosae, teeth, or Pacinian corpuscles. Muscle spindles appeared normal and had normal spiral endings in young 'wobblers'. In old animals some muscle spindles were atrophied and had thickened capsules, but only in regions where denervation atrophy of extrafusal fibres was very severe. The innervation of the muscle spindles was not studied in detail.

PRECLINICAL STAGE In the 19- and 22-day-old mice many abnormal nerve cells were found in the brainstem, in the ventral magnocellular reticular nucleus (Fig. 3), and in the motor nuclei of cranial nerves $V$ and VII. A few abnormal cells were found in the red

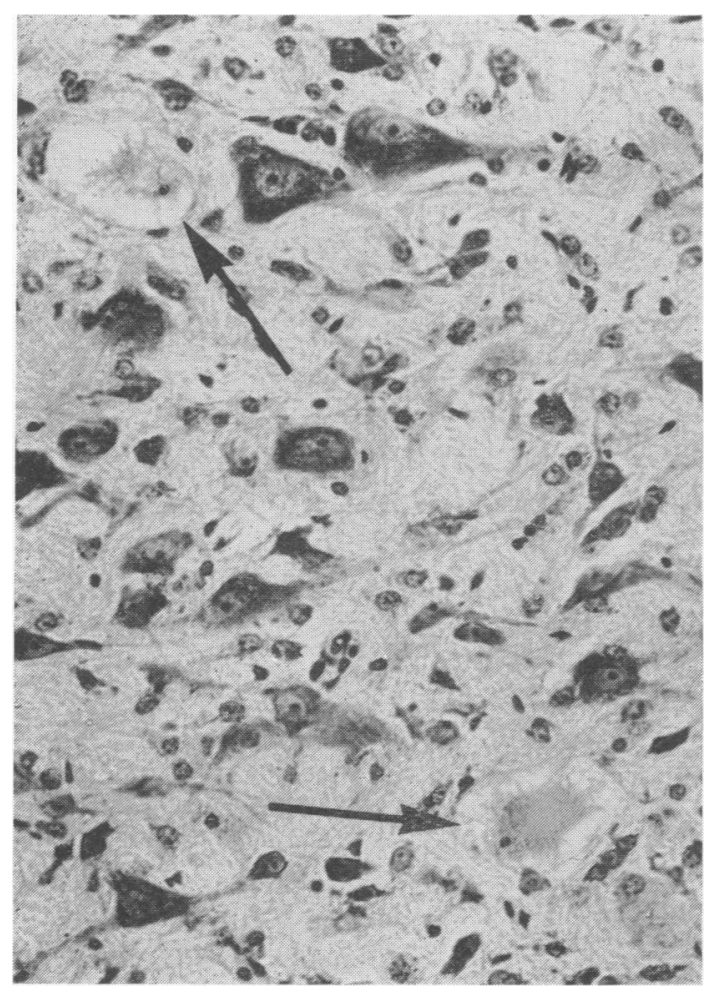

FIG. 3. Swollen and vacuolated nerve cells (arrows) in the magnocellular reticular nucleus of the medulla of a 19-dayold mouse killed before the onset of clinical signs. (Cresyl violet, $\times 250$.) nucleus, substantia nigra, anterior and posterior colliculi, and in the deep cerebellar nuclei. No abnormalities were seen in the cerebral cortex. In the spinal cord many abnormal cells were present in the ventral horns of the cervical region, but fewer in thoracic and lumbar levels.

In paraffin sections of skeletal muscle a few fibres with centrally placed nuclei were seen but no atrophied fibres were present. In the frozen silverimpregnated sections of the limb muscles, however, abnormalities were present in the nerve fibres. Fragmented axons were seen in some intramuscular nerve trunks and some motor fibres ended in bizarre club-shaped swellings instead of the fine terminal arborization normally seen. Many preterminal axons showed fine sprouting and innervated more than one muscle fibre.

YOUNG 'WOBBLER' MICE In these mice clinical abnormalities were clearly present. Nerve cells in various stages of degeneration were present in the brain-stem and spinal cord. They appeared to be more numerous in the ventral horn of cervical spinal cord than in brain-stem or thoracic and lumbar cord, though cell counts were not done. Silver impregna-

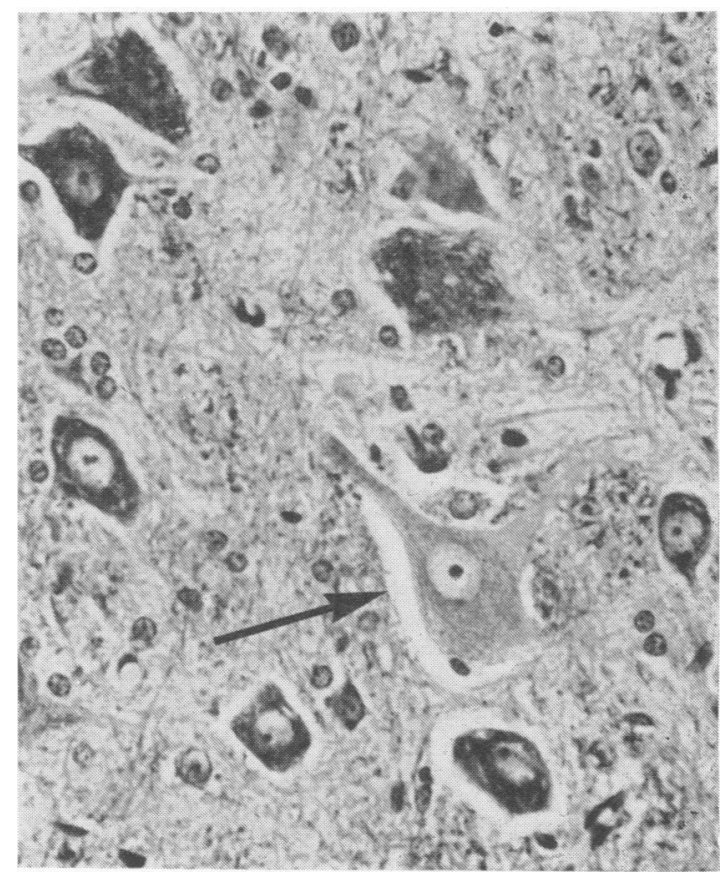

FIG. 4. Ventral horn cells of the cervical spinal cord of a 'wobbler' mouse 8 weeks old. One cell (arrow) shows early degenerative change. It is enlarged and has no stainable Nissl bodies. (Luxol-fast-blue/cresyl violet, $\times 400$.) 


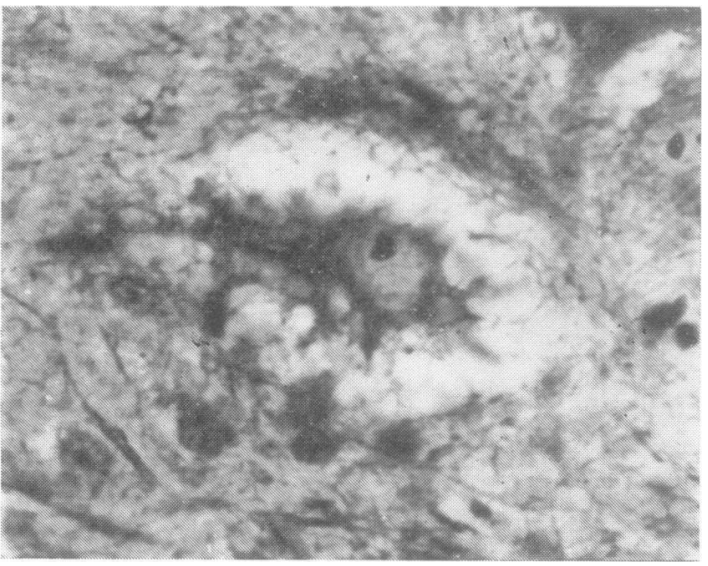

FIG. 5. Ventral horn cell in an advanced state of degeneration. The nucleus is surrounded by a mass of vacuoles. (Luxol-fast-blue/cresyl violet,$\times 800$.)

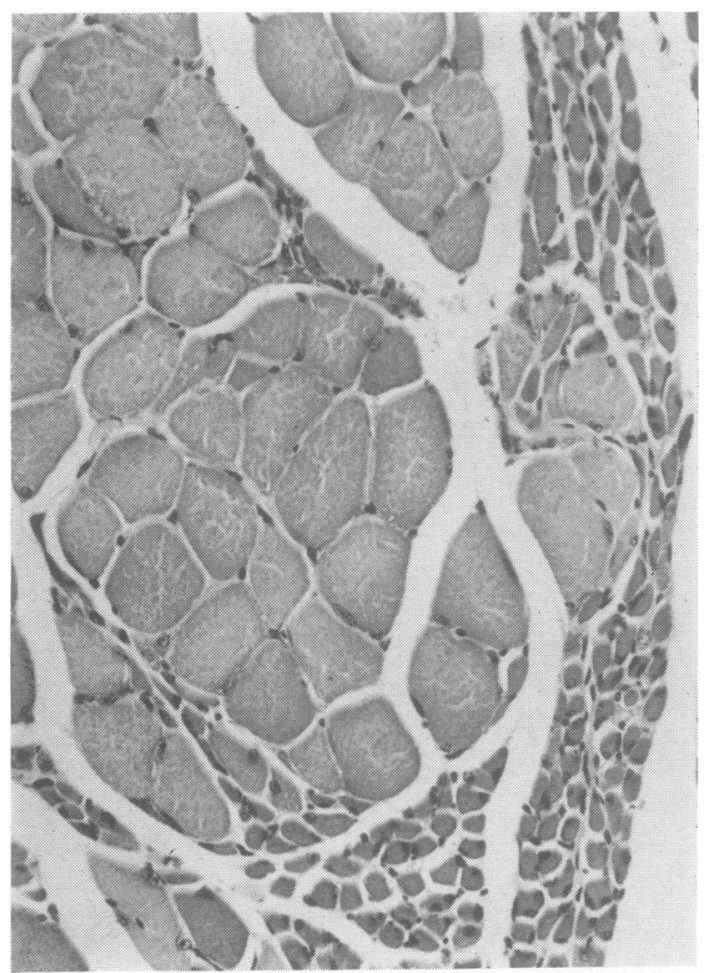

FIG. 7. Facial muscles of a 5-month-old 'wobbler' mouse. There is atrophy of some fascicles whilst others are normal, a pattern typical of partial motor denervation. ( $H$ and $E, \times 400$.)

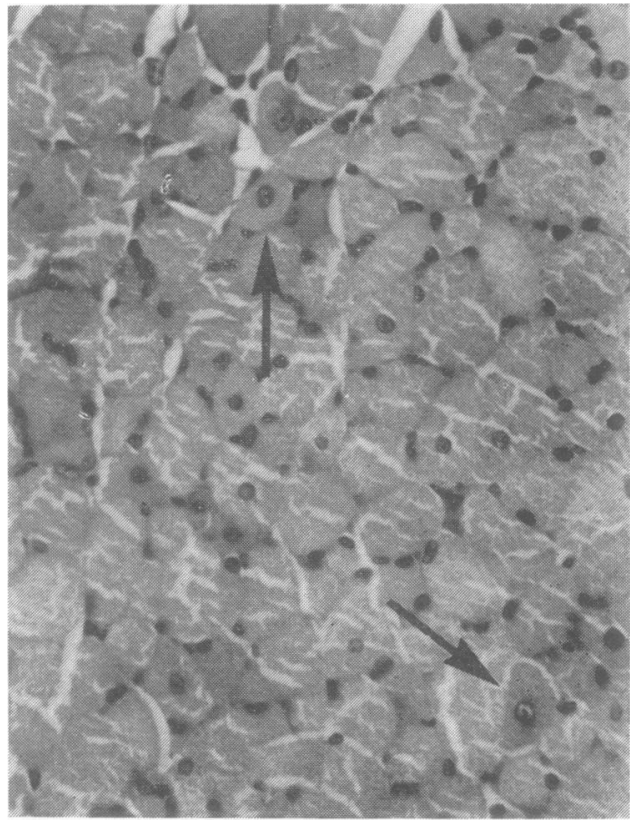

FIG. 6. Foreleg muscle of a 'wobbler' mouse 36 days old 겂 Early denervation changes are present. Many muscle fibre o (arrows to two) have centrally-placed nuclei and ase smaller than normal. ( $H$ and $E, \times 400$.)

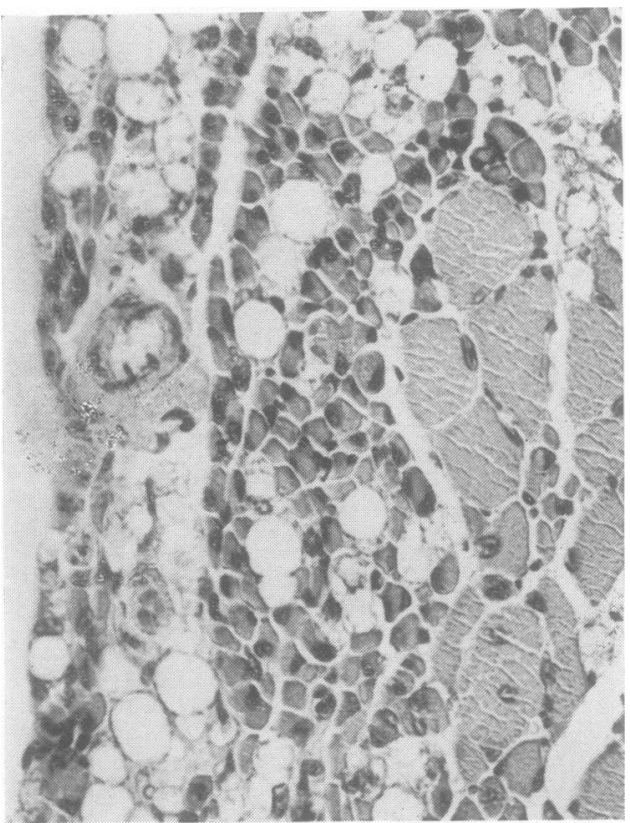

通

$\sigma$

FIG. 8. Forelimb muscle showing advanced denervation atrophy. There is fat between severely atrophied muscle fibres. $A$ bundle of normal-sized fibres is present. ( $H$ and $E$, $\sigma$ $\times$ 400.) 
tion of frozen sections of limb muscles now showed marked collateral sprouting of axons and many of the fine nerve fibres were beaded. The preterminal axons innervated several muscle fibres and some nerve endings were small and unbranched. The nerve sprouting occurred mainly from the myelinated part of the axon and not from the terminal arborization. Abnormalities in skeletal muscle fibres were now readily seen. Sarcolemmal nuclei were enlarged with prominent nucleoli and many muscle fibres contained centrally placed nuclei (Fig. 6). Atrophied muscle fibres were first seen in 6-7-week-old micethat is, two weeks after the onset of clinical weakness -and were situated at the periphery of the muscle bundles. Later there was atrophy of groups of muscle fibres (Fig. 7). These denervation changes were found in muscles of the head, neck, shoulder girdle, and forelimb more than in the hindlimb.

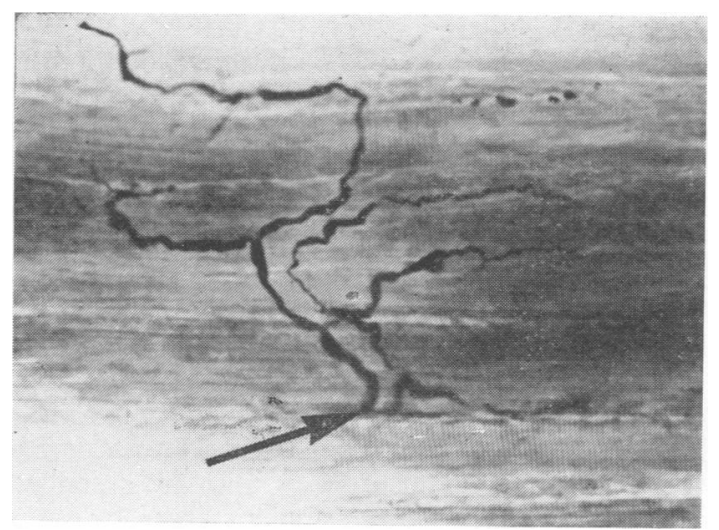

FIG. 9. Silver impregnation of muscle of a 4-month-old 'wobbler'. A single preterminal axon (arrow) branches repeatedly and innervates several muscle fibres. (Schofield, $\times$ 265.)
OLDER 'WOBBLER' MICE Degenerating nerve cells were seen and were still most numerous in cervical spinal cord. Grey and white matter of the spinal cord was smaller than in littermate controls, but the size of the spinal cord was not obviously out of proportion to the size of the animal. The pyramidal tracts appeared normal. In the ventral horn there seemed to be a reduction in the number of motor nerve cells. No astrocytic gliosis or microglial proliferation was seen in the spinal cord. The ventral roots were not fibrosed.

The skeletal muscles which were affected became more atrophied. Muscle fibres became progressively smaller in diameter and some muscles were largely replaced by fat. No muscle fibre necrosis and no 'target' fibres were seen at any stage of the disease. Studies of the innervation of the severely atrophied muscles showed a marked reduction in the number of motor nerve fibres, while many of the axons which were present showed collateral sprouting (Figs. 9 and 10). Thin beaded nerve fibres apparently ending in fatty tissue and not on muscle fibres were present. In mice which survived for more than a year occasional degenerating nerve cells were present in the ventral horns of the spinal cord. Evidence of early denervation was usually present in some muscles while in others the atrophy was advanced.

DISTRIBUTION OF DENERVATION ATROPHY The distribution of the skeletal muscles which showed denervation atrophy was remarkably similar in all the animals studied. Not every muscle was affected, but those which did show atrophy were affected on both sides of the body. For example, of the facial muscles, the platysma-innervated by the VIIth cranial nerve-was always severely and symmetrically affected while the masseters-innervated by the Vth cranial nerve-were at least partially preserved even in the longest survivors. The muscles

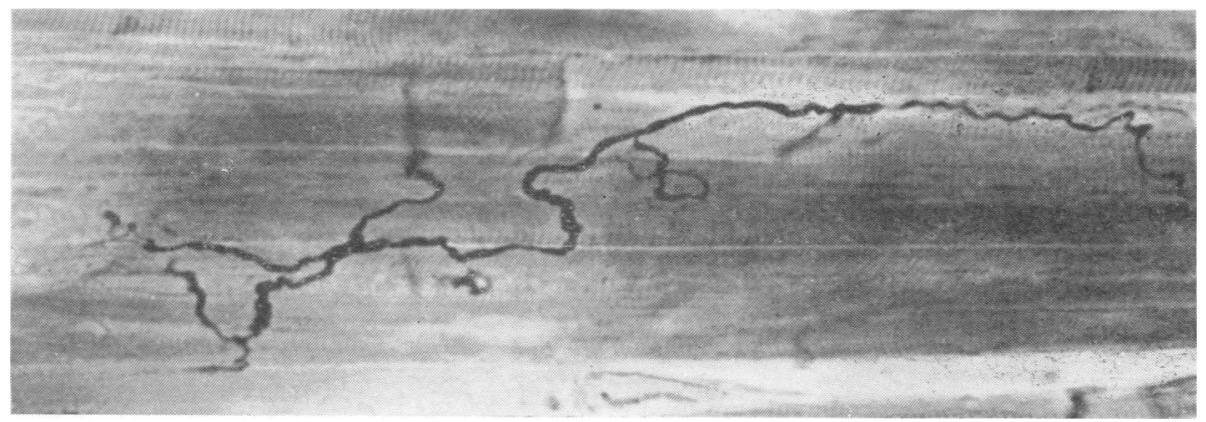

FIG. 10. Silver impregnation of muscle of a 'wobbler' showing one long nerve fibre with many sprouts. This is characteristic of partial motor denervation. (Schofield, $\times 340$.) 
of the neck and shoulder region were severely affected, while the forelimbs showed more severe atrophy proximally than distally. Trunk muscles and diaphragm were relatively spared and hindlimb muscles were less involved than those of the forelimb. In the hindlimb, proximal muscles were more atrophied than distal ones, and in some animals the only muscles below the knee to show denervation atrophy were the gastrocnemii.

\section{DISCUSSION}

The abnormalities which have been observed in the brain-stem and spinal cord of the 'wobbler' mouse indicate that this disease primarily affects motor nerve cells. The first abnormality seen in the motor neurones was swelling of the cell body and disappearance of Nissl substance. Later the cytoplasm became vacuolated. Andrews and Maxwell (1967) have studied the ventral horn cells of the 'wobbler' mouse with the electron microscope and observed that the perikaryon was filled with many small vesicles in some cells, while in other nerve cells the vesicles were large and almost replaced the cell. These abnormalities can be correlated well with the light microscopic changes described in the nerve cells in the present paper. The pathological findings suggest a primary degeneration of the nerve cell body and are not like the changes in the perikaryon secondary to axonal degeneration. It has been shown (Torvik and Heding, 1967) that the reaction to axonal injury in motor nerve cells of the nucleus of the facial nerve in the mouse is characterized by increased basophilia of the perikaryon and reduction in size of Nissl granules.

In the skeletal muscles the atrophy of muscle fibres occurred in groups and fascicles, a pattern characteristic of motor denervation. Sprouting and branching of preterminal motor nerve fibres, of the pattern seen in the skeletal muscles of these mice, are like those described as a response to partial motor denervation (Tello, 1907; Edds, 1950; Wohlfart and Hoffman, 1956). No necrosis of muscle fibres was seen at any stage of the disease and there was no evidence to suggest that this disease process primarily affects muscle fibres. The rapid accumulation of fat in the atrophied muscles of the 'wobbler' mouse is also seen in other forms of motor denervation in the mouse (atrophy after local injection of botulinum toxin: Duchen and Strich, 1968; atrophy after nerve section: authors' unpublished observations).

Nerve cell degeneration was seen in 3-week-old mice killed before the onset of detectable muscle weakness. In these animals there was already abundant sprouting from intramuscular axons. Clinical muscle weakness was detectable at about 4 weeks of age and atrophy of muscle fibres was first seen at $6 \frac{\bar{Q}}{\mathrm{C}}$ weeks. It seems likely, therefore, that re-innervation by collateral sprouting of intramuscular nerve fibres was able to compensate for the loss of motor neu- $\frac{c}{6}$ rones for some weeks.

In all the mice studied histologically the distribut

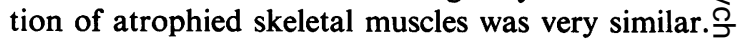
Some muscles were always relatively spared. The manner in which an hereditary defect can affect some. nerve cells but spare others of the same system is not $\Rightarrow$ clear. A relatively constant distribution of muscle $\stackrel{\omega}{+}$ weakness is also found in some hereditary neuro- $\frac{}{C}$ muscular diseases in man, such as peroneal muscular $\frac{\bar{\sigma}}{\bar{s}}$. atrophy, the juvenile form of muscular atrophy (Kugelberg and Welander, 1956) and in muscularฉ dystrophies. In the infantile form of motor neurone disease (Werdnig-Hoffmann disease) weakness is $\vec{\circ}$ first seen in the trunk muscles, but in the fully: developed disease abnormal motor nerve cells are $\vec{\omega}$ seen throughout brain-stem and spinal cord (Conel, 1938, 1940).

Sporadic or inherited cases of spinal motor neu- $\frac{7}{\omega}$ rone degeneration have occasionally been described in various animals (Innes and Saunders, 1962). The ${ }^{\circ}$ 'wobbler' mouse provides an example of an hereditary disease of motor nerve cells in a small laboratowio animal. Although the underlying causes of the disease? may differ from those in human diseases this mutafit ${ }_{\square}$ is a useful model for the study of many aspects $\sigma_{\mathrm{f}}^{\Phi}$ neuromuscular disorders.

\section{SUMMARY}

The clinical and pathological findings in an herecti- $\vec{\bullet}$ tary neuromuscular disorder in mice are described. This disease, known as 'wobbler', arose by spontaneous mutation and is transmitted by a single autosomal recessive gene $w r$. The condition is characterized by progressive muscular weakness and® wasting. Degenerating motor nerve cells were found $\mathbb{Q}$ in the brain-stem and spinal cord and there was $\vec{\Rightarrow}$ progressive motor denervation of skeletal muscle. $\frac{0}{3}$ The pathological findings indicate that in this hereditary disease there is a primary abnormality in the perikaryon of motor nerve cells.

We should like to thank Mr. A. R. Salliss, Mr. A. J. Davey, and Mr. I. J. Stiff for the technical work, and Mr.ं P. M. Taylor for the photographs. This work was supported by grants from the Research Fund of the Bethlem Royal and Maudsley Hospitals and from the $\frac{\mathrm{O}}{3}$ Muscular Dystrophy Associations of America, Inc.

\section{REFERENCES}

Andrews, J. M., and Maxwell, D. S. (1967). Ultrastructural features of anterior horn cell degeneration in the wobbler (wr) mouse. $N$ Anat. Rec., 157, 206 .

Beesley, R. A., and Daniel, P. M. (1956). A simple method for prepar- N ing serial blocks of tissue. J. clin. Path., 9, 267-268. 
Conel, J. L. (1938). Distribution of affected nerve cells in a case of amyotonia congenita. Arch. Neurol. Psychiat. (Chic.), 40, 337-351.

- (1940). Distribution of affected nerve cells in amyotonia congenita (second case). Arch. Path., 30, 153-164.

Duchen, L. W., Falconer, D. S., and Strich, S. J. (1966). Hereditary progressive neurogenic muscular atrophy in the mouse. $J$. Physiol. (Lond.), 183, 53-55P.

—, and Strich, S. J. (1968). The effects of botulinum toxin on the pattern of innervation of skeletal muscle in the mouse. Quart.J. exp. Physiol., 53, 84-89.

Edds, M. Y. Jr. (1950). Collateral regeneration of residual motor axons in partially denervated muscles. J. exp. Zool., 113, 517-552.

Falconer, D. S. (1956). Mouse News Lett., 15, 23.

Gallyas, F. (1963). Silver impregnation method for microglia. Acta Neuropath., 3, 206-209.

Grüneberg, H. (1952). The Genetics of the Mouse, 2nd ed., Martinus Nijhoff, The Hague.

- (1956). An Annotated Catalogue of the Mutant Genes of the House Mouse. (M.R.C. Mem. No. 33.) H.M.S.O., London.

Innes, J. R. M., and Saunders, L. Z. (1962). Comparative Neuropathology. Academic Press, New York.
Klüver, H., and Barrera, E. (1953). A method for the combined staining of cells and fibers in the nervous system. J. Neuropath. exp. Neurol., 12, 400-403.

Kugelberg, E., and Welander, L. (1956). Heredofamilial juvenile muscular atrophy simulating muscular dystrophy. Arch. Neurol. Psychiat. (Chic.), 75, 500-509.

Palmgren, A. (1948). A rapid method for selective silver staining of nerve fibres and nerve endings in mounted paraffin sections. Acta zool. (Stockh.), 29, 377-392.

Schofield, G. C. (1960). Experimental studies on the innervation of the mucous membrane of the gut. Brain, 83, 490-514.

Sidman, R. L., Green, M. C., and Appel, S. H. (1965). Catalog of the Neurological Mutants of the Mouse, Harvard Univ. Press, Cambridge, Mass.

Tello, F. (1907). Dégénération et régénération des plaques motrices aprés la section des nerfs. Trab. Lab. Invest. Biol. (Madrid), 5 , 117-149.

Torvik, A., and Heding, Anna, (1967). Histological studies on the effect of Actinomycin $D$ on retrograde nerve cell reaction in the facial nucleus of mice. Acta Neuropath., 9, 146-157.

Wohlfart, G., and Hoffman, H. (1956). Reinnervation of muscle fibers in partially denervated muscles in Theiler's encephalomyelitis of mice (mouse poliomyelitis). Acta psychiat. scand., 31, 345-365.

APPENDIX

\section{S. Falconer}

The gene wobbler ( $w r)$ arose by spontaneous mutation in the C57BL/Fa inbred strain, and was first detected in the progeny of one pair in 1955. It was maintained on the C57BL background for eight years, awaiting possible investigation. In order to facilitate the maintenance it was transferred to a non-inbred background in 1963.

Two proved heterozygotes when outcrossed produced a total of 21 female and 14 male offspring, all of which were normal. This proved the gene to be recessive. The segregation from proved heterozygous pairs is given in the Table. On the C57BL background there was a significant deficiency of $w r / w r$ homozygotes, when tested against the expectation of $25 \%$. The deficiency was greater in females than males, though not significantly so. The non-inbred matings showed a smaller and non-significant deficiency which, in this case, was less in females than in males. The two types of mating are, however, not significantly heterogeneous with respect to the ratios obtained, even when only the females are compared. Thus, there were undoubtedly fewer than the expected number of classified homozygotes in the C57BL families and possibly also in the noninbred families.

The cause of the deficiency of $w r / w r$ homozygotes was not identified. It seems unlikely to have been due to differential mortality between birth and classification, because the proportion of offspring that diedgiven also in the Table-was not higher where the deficiency was greater. Since classification cannot be made with certainty until a week or more after the mice are weaned at about 3 weeks of age, there was a possibility that some litters might have been prematurely discarded with some individuals erroneously classified as normal. This, however, does not seem to be the explanation because the deficiency was equally evident in litters that had been classified at two months or more. In the absence of identified postnatal causes, the deficiency must presumably be

TABLE

\begin{tabular}{|c|c|c|c|c|c|c|c|c|}
\hline & \multicolumn{6}{|c|}{ PHENOTYPES OF OFFSPRING FROM $+w r \times+w r$ MATINGS } & \multirow{2}{*}{\multicolumn{2}{|c|}{$\begin{array}{l}\text { Dead before } \\
\text { classification } \\
\text { (no.) }(\%)\end{array}$}} \\
\hline & Matings (no.) & Sex & $w r$ & + & Total & $\% w r$ & & \\
\hline Inbred & 28 & $\begin{array}{l}\text { Females } \\
\text { Males } \\
\text { Unknown } \\
\text { Total }\end{array}$ & $\begin{array}{r}45 \\
67 \\
-112\end{array}$ & $\begin{array}{l}234 \\
\frac{264}{498}\end{array}$ & $\begin{array}{l}279 \\
331 \\
\frac{710}{}\end{array}$ & $\begin{array}{l}16 \cdot 1 \\
20 \cdot 2 \\
\frac{18 \cdot 2}{}\end{array}$ & $\begin{array}{r}16 \\
24 \\
6 \\
46\end{array}$ & $\begin{array}{l}(5 \cdot 4) \\
(6 \cdot 8) \\
(7 \cdot 5)\end{array}$ \\
\hline Outbred & 9 & $\begin{array}{l}\text { Females } \\
\text { Males } \\
\text { Unknown } \\
\text { Total }\end{array}$ & $\begin{array}{c}22 \\
26 \\
48\end{array}$ & $\begin{array}{r}73 \\
97 \\
170\end{array}$ & $\begin{array}{r}95 \\
123 \\
\frac{7}{218}\end{array}$ & $\begin{array}{l}23 \cdot 2 \\
21 \cdot 1 \\
\frac{22}{22} \cdot 0\end{array}$ & $\begin{array}{r}10 \\
8 \\
5 \\
23\end{array}$ & $\begin{array}{l}(9 \cdot 5) \\
(6 \cdot 1) \\
(10 \cdot 1)\end{array}$ \\
\hline
\end{tabular}


ascribed to increased prenatal mortality. In this case the differential mortality of homozygotes in the C57BL families was $32 \%$.

If this greatly increased prenatal mortality is real, it will have an interesting bearing on the search for the primary genetic lesion. The clinical signs of disease do not appear until 3 weeks after birth, but even if the motor neurone degeneration started before birth, it is hard to believe that this would seriously reduce the viability of embryos. The primary genetic lesion may, therefore, be a more generalized metabolic defect of which the nerve cell degeneration is a later consequence. 